\title{
Biserica Ortodoxă Română din diaspora în viziunea Părintelui Virgil Gheorghiu
}

\author{
Maxim (Iuliu-Marius) MORARIU *
}

\begin{abstract}
The Romanian Orthodox Church in the Diaspora in Father Virgil Gheorghiu's Viewpoint. Using his writings, but also the documents provided by the Romanian Securitate Archives or the monographs, studies and articles dedicated to him, the author of the present research tries there to emphasize the way how the Romanian Orthodox from Paris is understood by the notorious writer and priest Constantin Virgil Gheorghiu. Translated in 40 languages and screened with Anthony Queen as a main character (The 25th Hour, 1967), he is for sure one of the most important voices of the Romanian culture from the 20th century and it is one of the thinkers that are still investigated and discovered nowadays. For this reason, we have tried to emphasize an important aspect of his work and activity and to show how, using his skills as a priest, he will present and preserve the Romanian spirituality in exile, how he managed to create relationships with the most important representatives of other Churches and in the same time, how he used his writer skills in order to promote his Church or to prevent the attempts of the Romanian Securitate to discredit it.
\end{abstract}

Keywords: diaspora, French exile, Romanians, Visarion Puiu, Romanian Securitate, preaching.

\section{Introducere}

Părintele Virgil Gheorghiu este, cu certitudine, un autor care trece printr-un proces de redescoperire în spațiul românesc contemporan și nu numai. Textele sale sunt încă traduse, numele său figurează pe frontispiciul unor studii, articole sau monografii

\footnotetext{
* Protosinghel, doctor în Științe Sociale la Universitatea Pontificală Angelicum, Roma, și cercetător asociat la Universitatea Pretoria din Africa de Sud.
} 
apărute recent, ${ }^{1}$ iar ideile lui fac încă obiectul unor cercetări interesante. $\mathrm{Cu}$ toate acestea, există încă suficiente aspecte ale

${ }^{1}$ Precum: Thierry Gillyboeuf, Constantin Virgil Gheorghiu - scriitorul calomniat, traducere din limba franceză, indice şi note de Maxim (Iuliu Marius) Morariu, București, Editura Sophia, 2019; Mircea Gheorghe ABRudan, „Părintele Virgil Gheorghiu pe urmele creștinilor din Liban”, în Ortodoxia Românească în istorie și contemporaneitate, Cluj-Napoca și Stockholm, Editura Renaşterea, Editura Felicitas, 2019, p. 499-501; Constantin CuBleȘAn, Escale în croazieră, ClujNapoca, Editura Grinta, 2011; Constantin CuBLEȘAN, Constantin Virgil Gheorghiu și aventura unei vieți literare, București, Editura Sophia, 2016; Loredana CuZMICI, „Destinul Internațional al unei cărți Românești ca Metaforă a Istoriei”, în Conference Proceedings of the Annual International Symposium Organized by "A. Philippide" Institute of Romanian Philology, București, Editura Academiei Române, 2015, p. 285-305; Mirela DRĂGOI, Constantin Virgil Gheorghiu - între lume și text, Galați, Editura Universității din Galați, 2009; Afif HADAM, Harmonies et Conflicts de Valeurs chez Constant Virgil Gheorghiu, București, Editura Universității din București, 1996; Ioan ICA jr., De la ,, Ora Veșnică” la ,, Ora 25 ” și retur, în Virgil GHEORGHIU, Tatăl meu, preotul care s-a urcat la cer, Sibiu, Editura Deisis, 2008, p. 5-15; Gabriela ILIUTA, „Constantin Virgil Gheorghiu, Exile dans la Coquille de L'ecriture du Roman «La Seconde Chance»", în Language, discourse and multicultural dialogue, First Volume, Târgu Mureş, Arhipelag XXXI Press, 2013, p. 541-555; Iuliu-Marius MORARIU, „Opera lui Virgil Gheorghiu între Literatură şi Autobiografie", în Anuarul Colegiului Academic de Performanță 2015-2016, Cluj-Napoca, Editura Presa Universitară Clujeană, p. 253-271; IuliuMarius MORARIU, Conflictul dintre Virgil Gheorghiu și Monica Lovinescu reflectat in Scrierile lui Mircea Eliade și Neagu Djuvara, în Doru SinACI, Emil ARBONIE (coord.), Administrație Românească Arădeană - Studii și Comunicări din BanatCrișana, „Vasile Goldiș” University Press, Arad, 2017, p. 578-585; Mirela DrAGOI, „Histoire et Recomposition Identitaire dans les Mémoires de Virgil Gheorghiu", în Intercultural communication and literature, 21 (2014), no. 1, p. 4048; Mirela DraGoI, „Questionnements Identitaires dans Les Mémoires de Virgil Gheorghiu", în Intercultural communication and literature, 22 (2015), no. 1, p. 93103; Mirela DragoI, „Le Discours de L'altérité dans L'Espionne de Virgil Gheorghiu", în Intercultural Communication and Literature, 23 (2016), no. 1, p. 305-321; Iuliu-Marius MorARIU, „Elemente ale Spiritualității Ortodoxe în Opera Literară a lui Virgil Gheorghiu", în Symposium, 23 (2016), no 1, p. 63-73; IuliuMarius MORARIU, „Insemnările de Război şi Importanţa lor pentru Constantin Virgil Gheorghiu", în Analele Aradului, 2 (2016), p. 712-721; Iuliu-Marius MORARIU, „Conflictul dintre Constantin Virgil Gheorghiu şi Monica Lovinescu, Reflectat în Memorialistica Exilului Parizian”, în Crisia, 47 (2017), no. 1, p. 183188; Iuliu-Marius Morariu, „Omul din Spatele Orei 25. Constantin Virgil Gheorghiu în Dosarele Securităţii”, în Sargetia, 44 (2017), no. 8, p. 373-381; Iuliu- 
biografiei și activității sale, ce pot fi valorificate și multe idei care-i poartă semnătura, ce se cer analizate și dezbătute.

Din acest motiv, ne-am propus ca în paginile următoare să ne oprim asupra unui element interesant și important al operei sale. Legat de viața sa din exil, pe care o consideră drept o „existență second-hand", situația Bisericii Ortodoxe Române din diaspora a constituit un element important al preocupărilor sale. În realizarea acestui demers vom analiza cu precădere scrierile publicate după anul 1948 și vom încerca să vedem care este dinamica vieții eclesiale Ortodoxe românești din spaţiul francez și cum se regăsește autorul, începând cu anul 1963, preot $^{3}$ al comunității românești din Franța. În acelaşi timp, vom compara, acolo unde va fi necesar, informațiile descoperite în lucrările care-i poartă semnătura cu cele păstrate în arhivele CNSAS (căci clericul a fost pe parcursul întregii sale vieți un om extrem de urmărit). ${ }^{4}$

\section{Biserica Ortodoxă Română din diaspora în viziunea părintelui Virgil Gheorghiu}

Ca fiu de preot, Virgil Gheorghiu a fost, precum va mărturisi în cel dintâi volum al memoriilor ${ }^{5}$, un om crescut în

Marius MORARIU, Ștefan JOSAN, Elements of spiritual autobiography in the Literary Works of Virgil Gheorghiu, în Research and Science Today 5 (2016), no. 11, p. 83-88.

2 Virgil Gheorghiu, A doua Șansă, trad. Gheorghiță Ciocioi, București, Editura Sophia, 2012, p. 5.

${ }^{3}$ Marinela D. Dorobanțu, Erwin Kretz, „Exile and Interculturalism - The Case of Five French Writers of Romanian Origin", în Studies of Science and Culture, 7 (2011), no. 3, p. 116.

4 Din dosare precum: Arhiva Consiliului Naţional pentru Studierea Arhivelor Securităţii (în continuare se va cita: A. C. N. S. A. S), M. F. I./Neamţ, rola 356; A. C. N. S. A. S, Fond Serviciul de Informaţii Externe (S. I. E), dosar nr. 4408/2;

A. C. N. S. A. S., Fond Serviciul de Informaţii Externe (S. I. E), dosar nr. 4408;

A. C. N. S. A. S., Fond Serviciul de Informaţii Externe (S. I. E), dosar nr. 349; A. C. N. S. A. S, Fond Informativ, cota I -185086, Dosar Gheorghiu Virgil; A. C.

N. S. A. S., Fond Informativ, cota I -234624, Dosar Gheorghiu Virgil.

5 Virgil GheORghiu, Memorii - martorul orei 25, trad. Sanda Mihăiescu-

Cârsteanu, București, Editura 100+1 Gramar, 1999. 
Biserică. A cunoscut încă de mic frumusețea slujbelor, a înțeles în profunzimea lui cultul Răsăritean și a fost la curent atât cu chestiuni precum schimbarea calendarului, care vor constitui ulterior subiectul unor texte precum romanul manuscris Dracula in Carpați $^{6}$, cât și cu alte aspecte de teologie, mai mult sau mai puțin profunde. Totodată, a evocat frumusețea vieții și a spiritualității românești de pe meleagurile nemțene în mai multe lucrări ale sale. În acelaşi timp, a vorbit despre chipul luminos al tatălui său ${ }^{7}$ și despre pilda şi jertfelnicia lui în paginile unei lucrări de o rară frumusețe.

Ulterior, a folosit timpul petrecut la Heidelberg spre a studia teologia, căci prins în angrenajul lucrurilor, nu a reuşit să facă acest lucru în țară ${ }^{8}$, iar când vremurile au permis, a devenit el însuși preot. Din această postură, a reușit nu doar să răspundă amplelor necesități pastorale ale comunității pe care le păstorea, ci și să întrețină și să dezvolte frumoase relații în plan ecumenic, cu reprezentanți ai altor culte, precum pastorul Charles Westphal $^{9}$ și să reprezinte Ortodoxia Românească în câteva rânduri chiar şi în locuri precum Geneva, locul în care se găsea sediul central al Consiliului Ecumenic al Bisericilor, unde va reuși să irite în mod constant Securitatea ${ }^{10}$, datorită faptului că nu putea fi cenzurat de către aceasta, în ciuda tuturor eforturilor depuse de către acoliții ei.

6 Constantin Virgil GheOrghiu, Dracula în Carpați. Roman inedit, trad. Gheorghiță Ciocioi, București, Editura Sophia, 2019.

7 Virgil GheORghiU, Tatăl meu, preotul care $s$-a urcat la cer, Sibiu, Editura Deisis, 2008; Virgil Gheorghiu, De la vingt-cinquieme heure a l'heure eternelle, Paris, Librairie Plon, 1965.

${ }^{8}$ Fapt despre care era la curent și Securitatea, după cum se poate vedea dintr-un raport publicat în anii '60 ai secolului trecut. A.C.N.S.A.S, Fond Serviciul de Informaţii Externe (S. I. E), dosar nr. 4408, f. 148.

9 Într-un raport al Securității, informatorul păstrează și o interesantă caracterizare pe care acesta i-o face părintelui Gheorghiu, fapt întru totul măgulitor pentru cel în cauză: (,,Westphal are o părere bună despre Gheorghiu. A afirmat că acesta este un om serios, se bucură de prestigiu şi apreciere, este un bun preot, dar în primul rând este scriitor". A. C. N. S. A. S., Fond Serviciul de Informaţii Externe (S. I. E), dosar nr. 4408/2, p. 25.

${ }^{10}$ A. C. N. S. A. S, Fond Serviciul de Informaţii Externe (S. I. E), dosar nr. 4408/2, f. $187-19$. 
Un aspect ce definește ampla activitate cu caracter ecumenic a lui Virgil Gheorghiu și care vorbește despre recunoașterea ei îl reprezintă apropierea sa de Patriarhul Ecumenic Athenagoras Spirou, căruia îi va și dedica o frumoasă biografie ${ }^{11}$. La rândul lui, ierarhul grec cu origini albaneze îl va decora cu cea mai înaltă distincție a instituției pe care o conducea, respectiv Crucea Patriarhală. Ulterior, situația complicată a creștinilor din Liban îi va atrage atenția și-l va determina să întreprindă în acest sens o frumoasă călătorie, despre care va scrie într-unul din volumele sale, prezentând nu doar istoria acestor meleaguri, ci și pledând pentru întreprinderea eforturilor necesare în vederea prezervării ei ${ }^{12}$.

Prin toate aceste aspecte, părintele V. Gheorghiu a reușit să creeze o frumoasă imagine Ortodoxiei Românești din exilul francez și să promoveze valori genuine precum dragostea, pacea, întrajutorarea frățească, sau dialogul în spațiul ecumenic. În același timp, a reuşit să-i transforme, pas cu pas, pe cei care îl urau la începutul preoției sale, în apropiaţi ai dânsului și colaboratori în realizarea de lucruri frumoase. E drept, Monica Lovinescu ${ }^{13}$, Virgil Ierunca $^{14}$ și Mircea Eliade îi vor rămâne mereu inamici și vor reuși să monteze împotriva lui atât autori francezi, cât și români precum Marin Preda ${ }^{15}$, însă impactul acuzelor lor va scădea în timp.

Ca preot și slujitor al altarului, părintele V. Gheorghiu va contribui cu condeiul la promovarea valorilor creștine în diaspora.

11 Virgil Gheorghiu, Viaţa Patriarhului Athenagoras, trad. Cristian Moldovan, Alba-Iulia, Editura Reîntregirea, 2009.

12 Virgil Gheorghiu, Christ au Liban, Monaco Ville, Éditions du Rocher, 1989.

13 Monica Lovinescu, Posteritatea contemporană - unde scurte, vol. III, București, Editura Humanitas, 1994, p. 271-274; Monica LovinesCu, La apa Vavilonului, București, Editura Humanitas, 1999, p. 65-67; Monica LOVINESCU, Jurnal, vol. 5- 1996-1997, București, Editura Humanitas, 2005, p. 146; Monica Lovinescu, Jurnal, vol. 6 - 1998-2000, București, Editura Humanitas, p. 160-161, p. 370.

${ }^{14}$ Virgil IERUNCA, Trecut-au anii... Fragmente de jurnal. Intâmplări şi accidente. Scrisori nepierdute, București, Editura Humanitas, 2000, p. 338-339.

${ }^{15}$ Cf. Marin PredA, Viața ca o pradă, ed. Nicolae Preda, ediţia a III-a, București, Editura Marin Preda, 1993, p. 301-303. 
Va dedica unor sfinți mari, respectiv Ambrozie al Milanului ${ }^{16}$ și Ioan Gură de Aur ${ }^{17}$, două frumoase biografii și în acelaşi timp își va arăta deschiderea înspre cunoaşterea altor spiritualităţi prin evocarea lui Mahomed ${ }^{18}$ şi cea a lui Martin Luther ${ }^{19}$ în paginile a două volume ample, cu caracter de monografie, în paginile cărora va scrie o istorie literaturizată. Prin toate aceste demersuri, a reuşit pe de-o parte să-i fortifice în credinţă pe cei încredințaţi lui înspre păstorire, oferindu-le modele demne de urmat (prin prezentarea detaliată și într-o manieră extrem de plăcută, a vieții celor doi mari sfinți) şi în acelaşi timp, a reuşit să arate deschiderea Ortodoxiei înspre dialogul cu alte spiritualități și credințe, bucurându-se de receptare și de atenție din partea liderilor lor.

$\mathrm{Ca}$ preot al diasporei, era conștient de rolul jucat de Ortodoxie în promovarea și prezervarea identității naționale. $\mathrm{Nu}$ era străin nici de faptul că existau multe presiuni şi încercări de discreditare a acestor formațiuni bisericești românești, rămase încă independente și nici de faptul că anumiți păstori harismatici reprezentau adevărate pietre de hotar în conservarea şi promovarea valorilor genuine ale Ortodoxiei în respectivul spațiu. Din acest motiv va dedica volumul Dumnezeu la Paris ${ }^{20}$ mitropolitului Visarion Puiu ${ }^{21}$, pe care îl considera un adevărat nedreptăţit al istoriei bisericești. În acest context, se va preocupa ca prin intermediul slujirii, al predicilor, pe care, după cum remarcă Thierry Gilyboeouf, unul dintre biografii săi ${ }^{22}$, le pregătea

16 Virgil GheOrghiu, Sfântul Ambrozie al Milanului, trad. Gheorghiță Ciocioi, București, Editura Sophia, 2013.

17 Virgil GHEORghiu, Sfântul Ioan Gură de Aur - Atletul lui Hristos, trad. Cornelia Ică, Sibiu, Editura Deisis, 2008.

18 Virgil GheORghiU, Viața lui Mahomed, trad. Gheorghiță Ciocioi, București, Editura Sophia, 2016.

${ }^{19}$ Virgil GheORGHIU, La jeunesse du Docteur Luther, Paris, Éditions du Plon, 1965.

20 Virgil Gheorghiu, Dumnezeu la Paris, trad. Gheorghiță Ciocioi, București, Editura Sophia, 2016.

${ }^{21}$ Ioan NeCulOIU, Marele Exterminator sau Căderea din Itinerarul Eshatologic în cel Terestru, în Virgil Gheorghiu, Marele Exterminator și Marele Sinod Ortodox, Făgăraş, Editura Agathon, 2008, p. 5.

${ }^{22}$ Thierry GiLlyboeuf, Constantin Virgil Gheorghiu - scriitorul calomniat,..., p. 72. 
cu multă acribie, să vorbească despre bogata moștenire culturală românească și rolul ei identitar. În același timp, cărțile sale, adresate între altele și credincioșilor pe care îi călăuzea, vor vorbi despre patrimoniul aparte al zonei Moldovei, despre mănăstirile de aici și despre celelalte lucruri importante care au definit această zonă. Astfel, de exemplu, în Dumnezeu la Paris, va descrie „minunile Moldovei”, respectiv mănăstirile din această zonă biecuvântată de Dumnezeu, care se înșiră ca adevărate mărgăritare pe versanţii Carpaţilor, îmbogăţind patrimoniul cultural şi cel spiritual al meleagurilor lui natale: „Minunile Moldovei. Sunt unice în lume. În nicio altă țară nu se poate vedea ceva asemănător, scria un expert în Artă Sacră. Văzută din exterior, fiecare biserică este o învântătoare piesă de decor, care trebuie admirată în cadrul său verde și alb - verdele dimprejur pe care se înalță biserica, albul incintei și cel al construcțiilor monastice, care formează un cadru dreptunghiular în jur"23.

În acelaşi timp, părintele Gheorghiu va fi la curent şi cu încercările Securității de a dezbina comunitatea de acolo, cu eforturile făcute în vederea discreditării păstorilor și cu toate celelalte eforturi concentrate înspre a distruge ceea ce, în acei ani reprezenta, în ciuda diviziunilor și conflictelor care existau între anumiți membri ai lor, un adevărat nucleu de rezistență. Mai-sus pomenitul roman va vorbi astfel despre complexa intrigă țesută de către regimul de la București în vederea discreditării episcopului din Paris și luării cu asalt a bisericii lui ${ }^{24}$. În fapt, folosind diferite metafore, Virgil Gheorghiu va vorbi aici despre cel pe care 1-a

${ }^{23}$ Virgil Gheorghiu, Dumnezeu la Paris,..., p. 30.

24 „Baxan e mulțumit. Nu este american ca să facă din succes o religie și un scop în viață, ci ca orice ființă omenească, e mulțumit când reușește în ceea ce a întreprins. Sunt mai puțin de trei luni de când Iuri Morcovescu și generalul Horodincă au venit la el, la Albina, în apropiere de București. I-au cerut să-l ucidă pe episcopul român din Paris înainte de solstițiul de iarnă. Înainte de 21 decembrie. Fără ca nimeni să-și dea seama că era la lucru, Baxan şi-a îndeplinit misiunea sa în jumătate de timp, în trei luni. În acea dimineață, 21 septembrie, echinocțiul de toamnă, episcopul era mort. Nimeni nu știa cum a lucrat Baxan. L-a ucis pe episcop rămânând tot timpul întins pe patul lui de spital”. Virgil GHeorghiu, Dumnezeu la Paris,..., p. 185. 
admirat întreaga viaţă, mitropolitul Visarion Puiu și despre modul în care mașinațiunile și dezinformarea practicată de către exponenții regimului de opresiune, îl vor transforma dintr-un lider spiritual într-un om bolnav și bătrân, condamnat să moară singur, abandonat și oropsit. Va încerca să-i aducă un omagiu postum și să arate că în ciuda tuturor eforturilor unora, asupra efigiei ierarhului nu s-a așternut negura uitării.

De asemenea, el arată că uneori comunitatea de aici, care era la curent cu anumite practici, se folosea de Biserică pentru a ajuta la eliberarea unora dintre cei persecutați, la cumpărarea $\operatorname{lor}^{25}$, asemenea celei pe care luteranii i-au organizat-o lui Richard Wurmbrand $^{26}$, ține să sublinieze concepția pe care o aveau comuniștii cu privire la legătura dintre Biserică și capitalism ${ }^{27}$, sau

25 "O putem cumpăra pe mama dumneavoastră. E doar o chestiune de bani. În fiecare duminică, la biserică, jumătate dintre persoanele care participă la slujbă sunt persoane cumpărate. Se plătește guvernului de la București un tarif. Căci există un tarif care oscilează precum toate valorile de la bursă. Nu știu care este prețul persoanelor pe piață. Acum câteva luni, se plăteau zece mii de dolari. Germanii care îi cumpără engros pe cetățenii lor din Polonia plătesc ceva mai ieftin. Ni s-a spus că varsă polonezilor opt mii de dolari pe cap de om". Virgil Gheorghiu, Dumnezeu la Paris,..., p. 128-129.

${ }^{26}$ Pentru mai multe informații în legătură cu acest subiect, a se vedea: Maria Hulber, In Sfera Tăcerii: Richard Wurmbrand în Dosarele Securității, Oradea, Editura Ratio et Revelatio, 2018; Adrian Vasile SABĂU, Literatură și Convertire: Steinhardt, Frossard, Wurmbrand, Iași, Editura Institutului European, 2011.

27 Astfel, de exemplu, unul dintre personajele care întruchipează comunismul și nomenclatura acestuia, spune la un moment dat în mai-sus pomenitul roman: „Capitalismul a fost inventat în secolul al XV-lea. Știați asta. În acel timp, fiecare branșă își avea uniforma ei. Preoții, ofițerii, brutarii, tâmplarii își aveau uniformele lor. Evul Mediu nu se terminase încă. Evul Mediu a fost epoca uniformelor. Chiar și prostituatele își aveau hainele lor. $\mathrm{Nu}$ puteau să-şi exercite meseria dacă nu purtau un capișon, ori o scufiță roșie. El s-a născut dintr-o dispută teologică. Până atunci, Biserica pretindea că banii nu puteau să facă pui. La sfârșitul Evului Mediu, Biserica a acceptat teoria cămătarilor, știind că banii pot să facă pui. Această schimbare teologică a dat naştere capitalismului. Primii capitaliști din lume au fost membrii familiei Fugger din Ausburg, Germania. Era o meserie nouă. Avea nevoie de o uniformă ca toate celelalte. Se va inventa una. Prima piesă vestimentară a uniformei capitaliste a fost acoperământul. Un acoperământ ca o bonetă tricotată cu fir de aur. Era 
să critice ingerințele politicului în Biserică ${ }^{28}$, respectând în același timp conducătorii eclesiastici ai vremii ${ }^{29}$.

Concepția părintelui Virgil Gheorghiu în legătură cu diaspora este, așadar, după cum se poate observa, una complexă. Cărțile sale, atitudinea pe care o adoptă în anumite situații, dar și alte aspecte similare vin să vorbească despre modul în care înțelegea el Biserica Ortodoxă Românească din exilul parizian și se raporta la aceasta.

\section{Concluzii}

În calitate de credincios și mai apoi de preot al comunității românești Ortodoxe din Paris, Virgil Gheorghiu a avut în cele peste cinci decenii petrecute aici, posibilitatea să cunoască Ortodoxia românească de pe aceste meleaguri, să o evalueze și chiar să o înțeleagă. Ca păstor și scriitor a slujit-o cu condeiul, cu vorba și cu inima, predicile sale fiind adevărate exortații la urmarea lui Hristos, iar activitatea lui din spațiul ecumenic, dar și din cel pan-ortodox, 1au transformat într-un mărturisitor și o personalitate apreciată a teologiei românești de peste hotare.

În același timp, ca scriitor, s-a îngrijit să-și nutrească duhovnicește turma, oferindu-le frumoase biografii ale unor părinți și ale unor personalităţi de seamă precum Sfinții Ambrozie al Milanului, Ioan Gură de Aur, Martin Luther sau Mahomed, iar când

uniforma capitaliștilor. Familia Fugger a fost prima care a purtat-o. Astăzi, semnele din afară ale bogătiei sunt: Cadillac-ul, Rols Royce-ul, iahturile, vilele somptuoase”. Virgil GHEORGHIU, Dumnezeu la Paris,..., p. 60-61.

${ }^{28}$ Cea mai reprezentativă lucrare în acest sens poate fi cu certitudine considerată: Virgil GHEORGHIU, Marele Exterminator și Marele Sinod Ortodox.

29 Astfel, de exemplu, un informator al Securității descria întrevederea dintre acesta și Patriarhul Justinian cu prilejul unei escale făcute de către capul Bisericii Ortodoxe Române la Geneva, în timpul unei călătorii și era stupefiat de respectul pe care acesta îl avea față de ierarh, clasificând comportamentul său drept bigot: „Sursa a remarcat că Constantin V. Gheorghiu face o oarecare paradă de bigotism. Astfel, când delegaţia bis[ericească] a pătruns în hotelul în care era cazat, Gheorghiu a îngenunchiat în faţa patriarhului şi a mitrop[olitului] J[ustin] Moisescu cărora cu capul plecat le-a sărutat cu smerenie mâinile". A. C. N. S. A. S., Fond Serviciul de Informaţii Externe (S. I. E), dosar nr. 4408/2, f. 43. 
a fost necesar, a deconspirat tentativele comuniștilor de a discredita comunitatea românească de aici şi personalitățile ei reprezentative din spațiul spiritualității.

$\cos 8$

\section{Bibliografie}

1. ABRUDAN, Mircea Gheorghe, „Părintele Virgil Gheorghiu pe urmele creștinilor din Liban", în Ortodoxia Românească în istorie și contemporaneitate, Cluj-Napoca și Stockholm, Editura Renașterea, Editura Felicitas, 2019.

2. A. C. N. S. A. S, M. F. I./Neamţ, rola 356.

3. A. C. N. S. A. S, Fond Serviciul de Informaţii Externe (S. I. E), dosar nr. 4408/2.

4. A. C. N. S. A. S, Fond Serviciul de Informaţii Externe (S. I. E), dosar nr. 4408.

5. A. C. N. S. A. S, Fond Serviciul de Informaţii Externe (S. I. E), dosar nr. 349.

6. A. C. N. S. A. S, Fond Informativ, cota I -185086, Dosar Gheorghiu Virgil.

7. A. C. N. S. A. S, Fond Informativ, cota I -234624, Dosar Gheorghiu Virgil.

8. CuBleșAn, Constantin, Constantin Virgil Gheorghiu și aventura unei vieți literare, București, Editura Sophia, 2016.

9. CuBleșAN, Constantin, Escale în croazieră, Cluj-Napoca, Editura Grinta, 2011.

10. CUZMICI, Loredana, „Destinul Internațional al unei cărți Românești ca Metaforă a Istoriei”, în Conference Proceedings of the Annual International Symposium Organized by "A. Philippide" Institute of Romanian Philology, București, ditura Academiei Române, 2015.

11. D'Esneval, Amaury, Gheorghiu, Puiseaux, Pardes, 2003.

12. DorobanțU, Marinela D., KRETZ, Erwin, „Exile and Interculturalism - The Case of Five French Writers of Romanian Origin", Studies of Science and Culture, 7 (2011), no. 3. 
13. DRAGOI, Mirela, „Histoire et Recomposition Identitaire dans les Mémoires de Virgil Gheorghiu", în Intercultural communication and literature, 21 (2014), no. 1.

14. DRAGOI, Mirela, „Questionnements Identitaires dans Les Mémoires de Virgil Gheorghiu, în Intercultural communication and literature, 22 (2015), no. 1.

15. DrAGOI, Mirela, „Le Discours de L'altérité dans L'Espionne de Virgil Gheorghiu", în Intercultural Communication and Literature, 23 (2016), no. 1.

16. GILlybOEUF, Thierry, Constantin Virgil Gheorghiu - scriitorul calomniat, traducere din limba franceză, indice şi note de Maxim (Iuliu Marius) Morariu, București, Editura Sophia, 2019.

17. GheORghIU, Virgil, A doua Șansă, trad. Gheorghiță Ciocioi, București, Editura Sophia, 2012.

18. GHEORGHIU, Virgil, Christ au Liban, Monaco Ville, Éditions du Rocher, 1989.

19. GHEORGHIU, Virgil, De la vingt-cinquieme heure a l'heure eternelle, Paris, Librairie Plon, 1965.

20. GHEORGHIU, Constantin Virgil, Dracula în Carpați. Roman inedit, trad. Gheorghiță Ciocioi, București, Editura Sophia, 2019.

21. GHEORGHIU, Virgil, Dumnezeu la Paris, trad. Gheorghiță Ciocioi, București, Editura Sophia, 2016.

22. GHEORGHIU, Virgil, La jeunesse du Docteur Luther, Paris, Éditions du Plon, 1965.

23. GHEORGHIU, Virgil, Memorii - martorul orei 25, trad. Sanda Mihăiescu-Cârsteanu, București, Editura 100+1 Gramar, 1999.

24. GHEORGHIU, Virgil, Sfântul Ambrozie al Milanului, trad. Gheorghiță Ciocioi, București, Editura Sophia, 2013.

25. GHEORGHIU, Virgil, Sfântul Ioan Gură de Aur - Atletul lui Hristos, trad. Cornelia Ică, Sibiu, Editura Deisis, 2008.

26. GHEORGHIU, Virgil, Tatăl meu, preotul care s-a urcat la cer, Sibiu, Editura Deisis, 2008.

27. GHEORGHIU, Virgil, Viața lui Mahomed, trad. Gheorghiță Ciocioi, București, Editura Sophia, 2016.

28. GHEORGHIU, Virgil, Viaţa Patriarhului Athenagoras, trad. Cristian Moldovan, Alba Iulia, Editura Reîntregirea, 2009.

29. HADAM, Afif, Harmonies et Conflicts de Valeurs chez Constant Virgil Gheorghiu, București, Editura Universității din București, 1996. 
30. HUlBer, Maria, In Sfera Tăcerii: Richard Wurmbrand în Dosarele Securității, Oradea, Editura Ratio et Revelatio, 2018.

31. ICA jr., Ioan, De la „Ora Veșnică” la „,Ora 25” și retur, în Virgil Gheorghiu, Tatăl meu, preotul care s-a urcat la cer, Sibiu, Editura Deisis, 2008, p. 5-15.

32. IERUNCA, Virgil, Trecut-au anii... Fragmente de jurnal. Intâmplări şi accidente. Scrisori nepierdute, București, Editura Humanitas, 2000.

33. ILIUTA, Gabriela, „Constantin Virgil Gheorghiu, Exile dans la Coquille de L'ecriture du Roman "La Seconde Chance»", în Language, discourse and multicultural dialogue, First Volume, Târgu Mureş, Arhipelag XXXI Press, 2013.

34. LOVINESCU, Monica, La apa Vavilonului, București, Editura Humanitas, 1999.

35. LOVINESCU, Monica, Jurnal, vol. 5- 1996-1997, București, Editura Humanitas, 2005.

36. LOVINESCU, Monica, Jurnal, vol. 6 - 1998-2000, București, Editura Humanitas.

37. LOVINESCU, Monica, Posteritatea contemporană - unde scurte, vol. III, Bucureşti, Editura Humanitas, 1994.

38. MORARIU, Iuliu-Marius, Josan, Ștefan, „Elements of spiritual autobiography in the Literary Works of Virgil Gheorghiu", în Research and Science Today, 5 (2016), no. 11.

39. MORARIU, Iuliu-Marius, „Conflictul dintre Constantin Virgil Gheorghiu şi Monica Lovinescu, Reflectat în Memorialistica Exilului Parizian", în Crisia, 47 (2017), no. 1.

40. MORARIU, Iuliu-Marius, Conflictul dintre Virgil Gheorghiu şi Monica Lovinescu, Reflectat în Scrierile lui Mircea Eliade și Neagu Djuvara, în Doru Sinaci, Emil Arbonie (coord.), Administrație Românească Arădeană - Studii și Comunicări din Banat-Crișana, „Vasile Goldiș” University Press, Arad, 2017.

41. MORARIU, Iuliu-Marius, „Elemente ale Spiritualității Ortodoxe în Opera Literară a lui Virgil Gheorghiu", în Symposium, 23 (2016), no 1.

42. MORARIU, Iuliu-Marius, ,Însemnările de Război şi importanţa lor pentru Constantin Virgil Gheorghiu", în Analele Aradului, 2 (2016).

43. MORARIU, Iuliu-Marius, „Omul din Spatele Orei 25. Constantin Virgil Gheorghiu în Dosarele Securităţii”, în Sargetia, 44 (2017), no. 8 . 
44. MORARIU, Iuliu-Marius, Opera lui Virgil Gheorghiu intre Literatură şi Autobiografie, în Anuarul Colegiului Academic de Performanță 2015-2016, Cluj-Napoca, Editura Presa Universitară Clujeană, Popa, Mircea, Istoria Literaturii Române de Azi pe Mâine. Volumul unu, București, Editura Semne, 2009.

45. NeCUloIU, Ioan, „Marele Exterminator sau Căderea din Itinerarul Eshatologic în cel Terestru", în Virgil Gheorghiu, Marele Exterminator şi Marele Sinod Ortodox, Făgăraş, Editura Agathon, 2008.

46. PREDA, Marin, Viaţa ca o pradă, ed. Nicolae Preda, ediţia a III-a, București, Editura Marin Preda, 1993.

47. SABĂU, Adrian Vasile, Literatură și Convertire: Steinhardt, Frossard, Wurmbrand, Iași, Editura Institutului European, 2011. 